\title{
Study of Acid-Base Disturbances in Patients with Liver Cirrhosis
}

\author{
Mohamed Alaa El-Din Nouh ${ }^{1}$, Hossam Ibrahim Mohamed ${ }^{1}$, \\ Basam Mohamed Esmaeil Masoud ${ }^{1}$, Abd El-Fattah Abd El-Rahman Yassin ${ }^{2}$ \\ ${ }^{I}$ Tropical Medicine Department, Faculty of Medicine, Menoufia University, Menoufia, Egypt \\ ${ }^{2}$ Mansoura Fever Hospital, Mansoura Egypt
}

Corresponding

Author:

Abd El-Fattah Abd

El-Rahman Yassin

Mobile:

$+201007585268$

E mail:

abdoyassen1983@

yahoo.com

Key words: liver cirrhosis, acid base balance

disorders, respiratory alkalosis
Background and study aim : Acid base disturbances occur frequently in the setting of liver diseases. As liver's metabolic function worsen, particularly in the setting of renal dysfunction, haemodynamic compromise, and hepatic encephalopathy, acid base disorders ensue. The aim of this study was to assess acid base disturbances in patients with liver cirrhosis.

Patients and Methods: The present study was conducted on 60 cirrhotic patients, as well as 20 healthy persons of matched age and sex as a control group. Diagnosis of cirrhosis was done by clinical examination, ultrasonographic findings and laboratory investigations. Patients and controls were subjected to the following:Full history taking, Thorough clinical examination, Abdominal ultrasound examination, Laboratory investigations including: $\mathrm{CBC}$, Liver function

\section{INTRODUCTION}

The liver is an important organ in acidbase physiology. It is a metabolically active organ which may be either a significant net producer or consumer of hydrogen ions. The acid- base roles of the liver include: carbon dioxide production from complete oxidation of substrates, metabolism of organic acids anions such as lactate, ketone and amino acids. The conversion of ammonium (NH4) to urea in the liver, synthesis of plasma proteins: except immunoglobulins [1].

Albumin is one of plasma proteins synthesized by the liver having many roles in acid-base physiology as it is considered as the major nonvolatile weak acid present in plasma, hypoalbuminemia causes a metabolic alkalosis. It is the major unmeasured anion in the plasma which contributes to the normal value of anion gap. It acts as an extra cellular buffer for $\mathrm{CO}_{2}$ tests, serum creatinine, Arterial blood gases to evaluate blood $\mathrm{PH}, \mathrm{HCO}_{3}$, pressure of carbon dioxide and pressure of oxygen.

Results: There was highly significant difference in $\mathrm{PH}, \mathrm{PCO}_{2}, \mathrm{PO}_{2}$, and $\mathrm{HCO}_{3}$ and $\mathrm{SO}_{2}$ between both groups. The common acid base disorder was respiratory alkalosis. However, other disorders can be seen. Change in acid base balance was as following: Child's A group; no change in acid base balance. Child's B group; 75\% no changes in acid base balance with $20 \%$ respiratory alkalosis and 5\% metabolic alkalosis. Child's C group; 70\% respiratory alkalosis with $15 \%$ respiratory acidosis and $15 \%$ metabolic alkalosis.

Conclusion: These result declare the presence of multiple and mixed acid base disorder in cirrhotic patients

and fixed acids, thus an abnormal level can cause metabolic acid-base disorder [2]. Hepatic disorders are often associated with acid base disorders. The most common disturbances in chronic liver diseases are respiratory alkalosis followed by metabolic alkalosis [3]. Acid-base disturbances in patients with chronic severe hepatitis, liver cirrhosis, ascites and patients with hepatic encephalopathy is often alkalosis. Alkalosis indicates that the kidneys have increased their $\mathrm{HCO}_{3}-$ reabsorption [4]. This may result from toxic stimulation of respiratory center by ammonium from administration of alkalies as citrate in transfusions or with potassium supplements or from hypokalemia. Since urea synthesis consumes bicarbonate thus progressive loss of urea cycle capacity is associated with increased plasma bicarbonate level (metabolic alkalosis) and ammonia excretion by the kidney [5]. 
Acid-base and potassium disorders occur frequently in the setting of liver disease. As the liver's metabolic function worsens, particularly in the setting of renal dysfunction, hemodynamic compromise, and hepatic encephalopathy, acidbase disorders ensue [6]. Effective treatment of acid-base disturbance will be valuable in prevention of hepatic encephalopathy [7]. The aim of present study was to evaluate the acid base disturbances in arterial blood gases in patients with liver cirrhosis.

\section{PATIENTS AND METHODS}

A total of 60 patients with liver cirrhosis were selected after giving a written informed consent, they were selected out from 200 patients admitted at Mansoura University Hospitals in the period between April 2013 and December 2013. They were $33(55 \%)$ males and 27 (45\%) females and their ages were ranging from 33 to 70 years, in addition 20 healthy persons of matched age and sex served as a control group. Diagnosis of cirrhosis based on clinical examination, ultrasonographic findings and laboratory investigations.

\section{Patients and controls were classified into the following groups:}

Group I : Comprised 60 cirrhotic patients, they were subdivided into 3 subgroups according to modified Child-Pugh classification :

- Group Ia: Comprised 20 cirrhotic patients (Child's grade A)

- Group Ib: Comprised 20 cirrhotic patients (Child's grade B)

- Group Ic: Comprised 20 cirrhotic patients (Child's grade C)

Group II: Comprised 20 healthy controls.

Patients and controls were subjected to the following:

1. Through history taking.

2. Clinical assessment with special emphasis on manifestations of liver cell failure.

3. Abdominal ultrasound examination.

4. Laboratory investigations:

- $\mathrm{CBC}[8]$.

- Urine analysis .

- Liver function tests namely alanine transaminase (ALT), aspartate transaminase (AST), serum bilirubin, serum albumin, INR level [9].

- Fasting blood sugar and post prandial blood sugar [10].

- Serum creatinine [11].

- Serum electrolytes: sodium, potassium.
- Arterial blood gases (ABG) to evaluate blood $\mathrm{PH}, \mathrm{HCO}_{3}$, pressure of carbon dioxide $\left(\mathrm{PCO}_{2}\right)$ and pressure of oxygen $\left(\mathrm{PO}_{2}\right)$. Any venous samples was discard [12]

\section{Statistical analysis:}

Data were tabulated, coded then analyzed using the computer program SPSS (Statistical package for social science) version 17.0. Descriptive statistics were calculated in the form of: Mean, Standard deviation $( \pm \mathrm{SD})$, Minimum and maximum and Frequency (No and \%). In the statistical comparison between the different groups, the significance of difference was tested using one of the following tests: ANOVA (analysis of variance): Used to compare between more than two groups of numerical (parametric) data followed by posthoc LSD for multiple comparisons. Inter-group comparison of categorical data was performed by using chi square test $\left(\mathrm{X}^{2}\right.$-value). A P value $<0.05$ was considered statistically significant. And a $\mathrm{P}$ value $<0.0001$ was considered highly significant in all analyses.

\section{RESULTS}

\section{Demographics of the studied groups}

There was no significant difference between the liver cirrhosis group and healthy controls and among subgroups of liver cirrhosis regarding the age and sex of patients. They were 33 (55\%) males and $27(45 \%)$ females and their ages were ranging from 33 to 70 years with a mean value of $41.35 \pm 5.81$ years in Group Ia, 53.95 \pm 7.51 years in Group Ib and $55.35 \pm 9.4$ years in Group Ic. Manifestations of liver cell failure were present in various proportions of cirrhotic groups. $\mathrm{HCV}$ infection was present in the majority of cirrhotic patients, while HBV infection was absent. HCV$\mathrm{Ab}$ and HBsAg were absent in all Group II persons. Ultrasonographic features of cirrhosis were present in all cirrhotic groups. Cirrhosis was mixed with peri-portal fibrosis in some patients of Group Ia, Ib and Ic.

\section{Biochemistry of the studied groups}

The mean value of hemoglobin concentration and platelet counts in cirrhotic groups (Ia,Ib,Ic) were significantly lower than that of Group II. On the other hand, there was no significant difference between the studied groups as regard mean total leucocytic and RBCs counts (Table 1). The mean value of hemoglobin concentration in cirrhotic groups (Group Ia, Group Ib and 
Group Ic) were significantly lower than hemoglobin concentration in Group II (non cirrhotic). The mean value of platelet count of Group $\mathrm{Ib}$ and Group Ic were significantly lower than that of Group Ia.

The mean values of serum Bilirubin in Group Ib and Group Ic were significantly higher than that of Group Ia and Group II. The present study showed that the mean values of serum bilirubin in Group Ib and Group Ic were significantly higher than that of Group II and Group Ia. The mean value in Group Ic was significantly higher than that of Group Ia. While, there was no significant difference between Group Ia and Group II (Table 2).

The mean values of serum albumin in Group $\mathrm{Ib}$ and Group Ic were significantly lower than that of Group Ia and Group II. The mean values of INR were significantly higher in Group Ib than that of Group Ia and significantly higher in Group Ic than in Group Ia and Group Ib. Meanwhile the values of INR in Group II were lower than that in Group Ib and Group Ic (Table 2).

The mean values of ALT in Group II and Group Ic were significantly lower than that in Group Ia and Group Ib. The mean values of AST in Group II were significantly lower than that in Group Ia, Group Ib and Group Ic (Table 3).

\section{Acid base and electrolyte disturbances of the studied patients}

In the present study initial assessment ABGs (Table 4) were done and both groups showed that significant difference in PH between Group Ic and Group Ia and Group Ib. As well as significant difference between Group II and Group Ic (Fig. 1). There was a highly significant difference in arterial $\mathrm{PH}, \mathrm{PCO}_{2}, \mathrm{PO}_{2}, \mathrm{HCO}_{3}$ and $\mathrm{SO}_{2}$ between both groups. Also there was significant difference between Group Ic and Group Ia and Group Ib in $\mathrm{PH}, \mathrm{PCO}_{2}$ and $\mathrm{HCO}$. But there was no significant difference between both groups regarding serum $\mathrm{Na}^{+}$and serum $\mathrm{K}^{+}$levels.

The reported acid-base disorders in the studied groups revealed that Group Ia was normal, Group Ib: $20 \%$ respiratory alkalosis, 5\% metabolic alkalosis and 75\% normal, Group Ic: $70 \%$ respiratory alkalosis, $15 \%$ metabolic alkalosis and $15 \%$ respiratory alkalosis. There was highly significance difference between Group I and group II (Table 5).

The common acid base disorder was respiratory alkalosis (Table 5), however, metabolic alkalosis, respiratory acidosis and metabolic acidosis all could also be seen (Fig. 2).

Also $\mathrm{PCO}_{2}$ there is significant difference (Table 4) between Group Ic and Group Ia and Group Ib. Again, there is significant difference between Group II and Group Ic (Fig. 3).

$\mathrm{HCO}_{3}$ there is significant difference (Table 4) between Group Ic and Group Ia, Group Ib and significant difference between Group II and Group Ic (Fig. 4).

As regard $\mathrm{SO}_{2}$ there is significant difference between Group Ib, Group Ic in relation to Group Ia as well as significant difference between Group II and Group Ib and Group Ic (Table 4).

There is low significant increase in serum $\mathrm{Na}^{+}$ between Group Ib and Group Ic than Group II (Table 4).

As regard $\mathrm{K}^{+}$there is low significant decrease (Table 4) in Group Ic in relation to Group Ia and Group II in relation to Group Ic (Fig. 5).

Table (1): Haematological profile in studied groups

\begin{tabular}{|c|c|c|c|c|c|c|c|c|c|}
\hline & & \multicolumn{2}{|c|}{ Hemoglobin } & \multicolumn{2}{|c|}{ RBC } & \multicolumn{2}{|c|}{ WBC } & \multicolumn{2}{|c|}{ PLATLETS } \\
\hline & & Mean \pm SD & Range & Mean \pm SD & Range & Mean \pm SD & Range & Mean \pm SD & \begin{tabular}{|l|} 
Range \\
\end{tabular} \\
\hline \multirow{3}{*}{ Group I } & GIa & $11.85 \pm 1.46$ & $8.80-14.30$ & $4.49 \pm .46$ & $3.80-5.30$ & $6.63 \pm 1.79$ & $4.20-9.70$ & $169.15 \pm 34.76$ & $112.00-234.00$ \\
\hline & $\mathrm{GIb}$ & $10.39 \pm .93^{\mathrm{a}}$ & $8.70-12.30$ & $4.78 \pm .66$ & $3.70-6.20$ & $7.00 \pm 1.88$ & $3.60-9.60$ & $121.10 \pm 33.35^{\mathrm{a}}$ & $81.00-190.00$ \\
\hline & GIc & $9.00 \pm .90^{\mathrm{ab}}$ & $7.60-10.70$ & $4.49 \pm .47$ & $3.80-5.30$ & $7.42 \pm 1.31$ & $4.90-9.80$ & $93.40 \pm 10.14^{\mathrm{ab}}$ & $76.00-118.00$ \\
\hline \multicolumn{2}{|c|}{ Group II } & $13.02 \pm 1.26^{\mathrm{abc}}$ & $11.20-15.40$ & $4.60 \pm .48$ & $3.80-5.30$ & $6.64 \pm 1.81$ & $3.90-9.70$ & $260.00 \pm 42.77^{\mathrm{abc}}$ & $193.00-321.00$ \\
\hline \multicolumn{2}{|l|}{$\mathrm{F}$} & \multicolumn{2}{|c|}{45.265} & \multicolumn{2}{|c|}{1.404} & \multicolumn{2}{|c|}{0.963} & \multicolumn{2}{|c|}{100.502} \\
\hline \multicolumn{2}{|c|}{$\mathrm{P}$} & \multicolumn{2}{|c|}{$<0.001$} & \multicolumn{2}{|c|}{0.248} & \multicolumn{2}{|c|}{0.415} & \multicolumn{2}{|c|}{$<0.001$} \\
\hline
\end{tabular}

G: group, RBCs: Red blood cells, WBCs: White blood cells, SD: standard deviation, P: Probability, a: significance relative to GIa, b: significance relative to GIb, c: significance relative to GIc 
Table (2): Results of Bilirubin -Albumin -INR of studied groups

\begin{tabular}{|c|c|c|c|c|c|c|c|}
\hline \multicolumn{2}{|c|}{} & \multicolumn{2}{c|}{ Bilirubin } & \multicolumn{2}{c|}{ Albumin } & \multicolumn{2}{c|}{ INR } \\
\cline { 3 - 8 } \multicolumn{2}{|c|}{} & Mean \pm SD & Range & Mean \pm SD & Range & Mean \pm SD & Range \\
\hline \multirow{3}{*}{ Group I } & GIa & $0.98 \pm .22$ & $0.70-1.40$ & $4.23 \pm .40$ & $3.60-4.90$ & $1.04 \pm .11$ & $0.87-1.20$ \\
\cline { 2 - 8 } & GIb & $1.36 \pm .25^{\mathrm{a}}$ & $1.10-1.90$ & $3.68 \pm .49^{\mathrm{a}}$ & $2.70-4.30$ & $1.45 \pm .24^{\mathrm{a}}$ & $1.10-1.90$ \\
\cline { 2 - 8 } & GIc & $2.26 \pm .52^{\mathrm{ab}}$ & $1.60-2.90$ & $2.34 \pm .48^{\mathrm{ab}}$ & $1.60-3.20$ & $1.70 \pm .19^{\mathrm{ab}}$ & $1.30-1.90$ \\
\hline Group II & $0.88 \pm .17^{\mathrm{bc}}$ & $0.60-1.20$ & $4.25 \pm .43^{\mathrm{bc}}$ & $3.74-4.90$ & $0.89 \pm .23^{\mathrm{bc}}$ & $0.00-1.10$ \\
\hline F & \multicolumn{2}{|c|}{76.634} & \multicolumn{2}{c|}{78.973} & \multicolumn{2}{c|}{70.714} \\
\hline P & \multicolumn{2}{|c|}{$<0.001$} & \multicolumn{2}{c}{$<0.001$} & \multicolumn{2}{c|}{$<0.001$} \\
\hline
\end{tabular}

G: group, SD: standard deviation, P: Probability, a: significance relative to GIa, b: significance relative to GIb c: significance relative to GIc

Table (3): Results of Alanine amino transferase, Aspartate amino transferase and creatinine

\begin{tabular}{|c|c|c|c|c|c|c|c|}
\hline \multicolumn{2}{|c|}{} & \multicolumn{2}{c|}{ ALT } & \multicolumn{2}{c|}{ AST } & \multicolumn{2}{c|}{ Creatinine } \\
\cline { 3 - 8 } \multicolumn{2}{|c|}{} & Mean \pm SD & Range & Mean \pm SD & Range & Mean \pm SD & Range \\
\hline \multirow{3}{*}{ Group I I } & GIa & $50.85 \pm 19.91$ & $23.00-89.00$ & $58.65 \pm 18.62$ & $33.00-89.00$ & $.95 \pm .20$ & $.60-1.30$ \\
\cline { 2 - 8 } & GIb & $54.90 \pm 15.63$ & $32.00-87.00$ & $60.05 \pm 14.30$ & $24.00-82.00$ & $1.03 \pm .23$ & $.60-1.40$ \\
\cline { 2 - 8 } & GIc & $34.85 \pm 14.53^{\text {b }}$ & $12.00-68.00$ & $39.35 \pm 10.84^{\mathrm{ab}}$ & $19.00-61.00$ & $1.14 \pm .20^{\mathrm{a}}$ & $.76-1.40$ \\
\hline Group II & $26.90 \pm 7.25^{\mathrm{ab}}$ & $12.00-38.00$ & $27.85 \pm 5.96^{\mathrm{abc}}$ & $16.00-36.00$ & $.90 \pm .17^{\mathrm{c}}$ & $.67-1.20$ \\
\hline F & \multicolumn{2}{|c|}{15.4} & \multicolumn{2}{c|}{27.6} & \multicolumn{2}{c|}{5.4} \\
\hline P & \multicolumn{2}{|c|}{$<0.001$} & \multicolumn{2}{c|}{$<0.001$} & \multicolumn{2}{c|}{0.002} \\
\hline
\end{tabular}

G: group, SD: standard deviation, P: Probability, a: significance relative to GIa, b: significance relative to GIb, c: significance relative to GIc

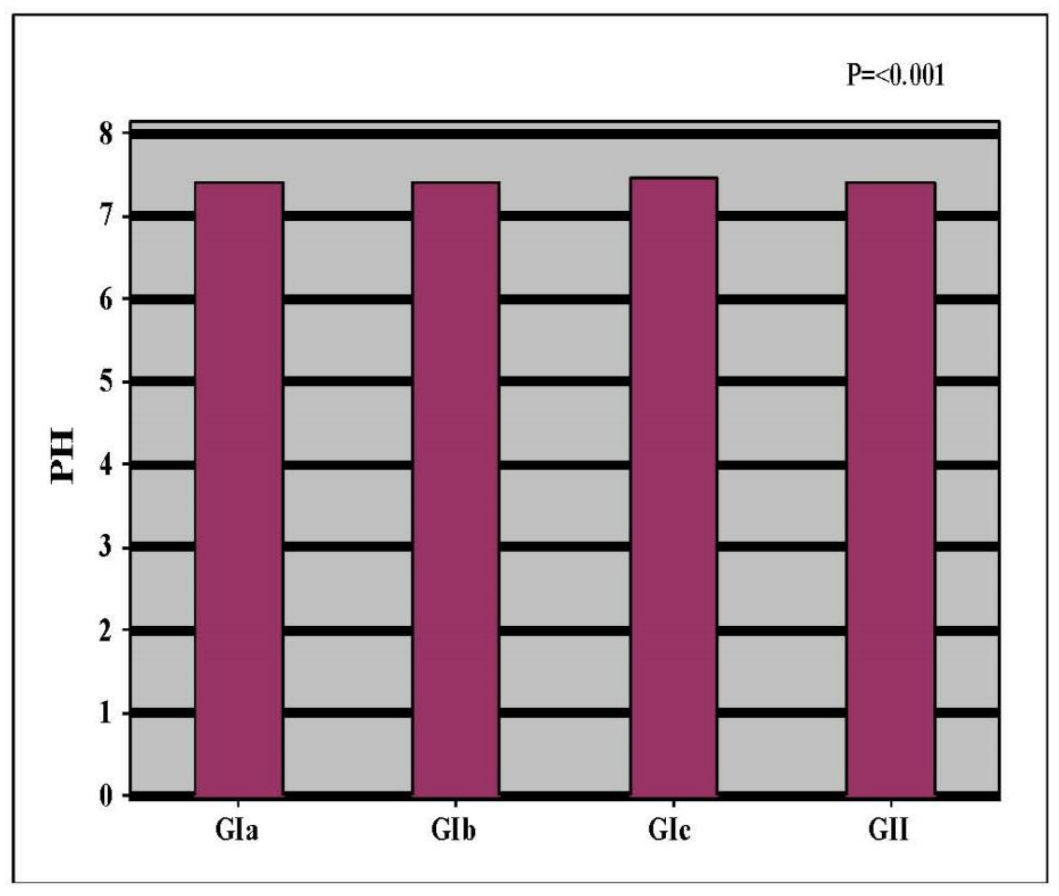

Fig. (1) : Results of PH of studied groups (G: group) 


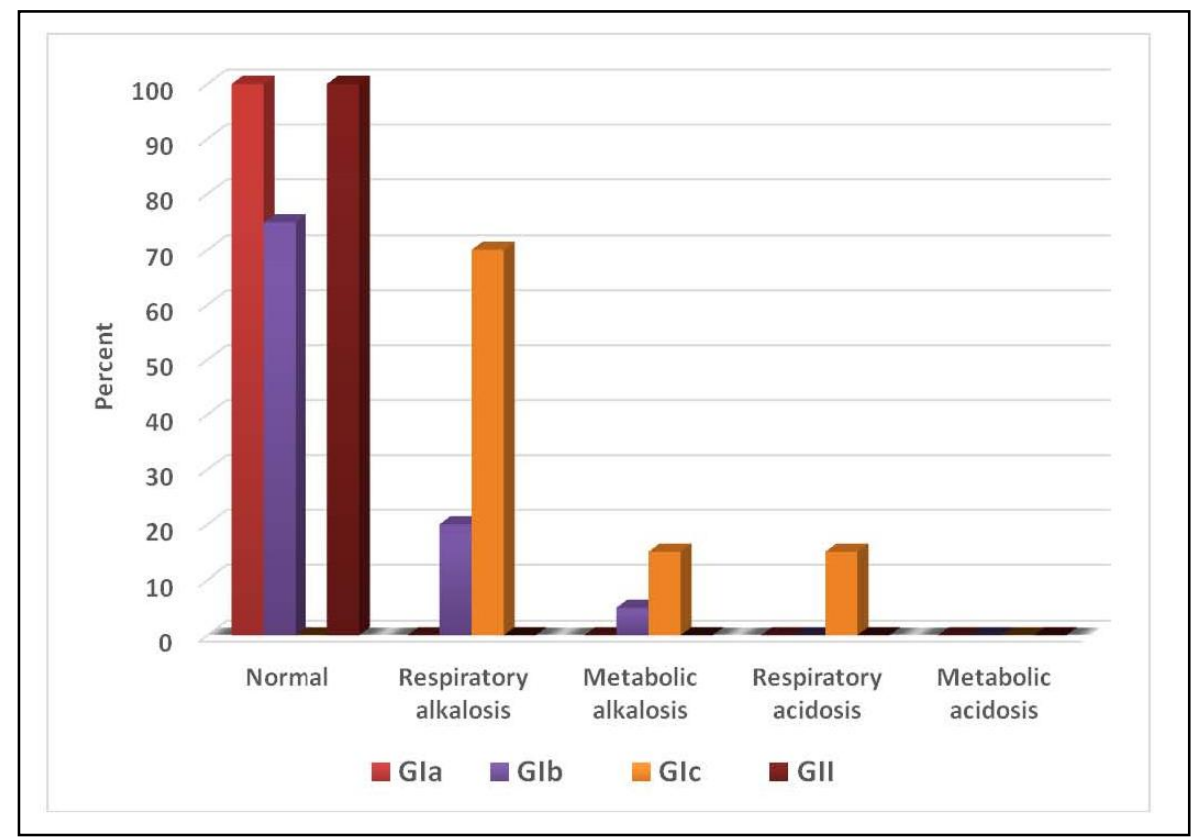

Fig. (2) : Acid-base status in the studied groups

Table (4) : Results of Arterial blood gases of studied groups

\begin{tabular}{|c|c|c|c|c|c|c|c|c|c|c|}
\hline & \multicolumn{6}{|c|}{ Group I } & \multirow{2}{*}{\multicolumn{2}{|c|}{ Group II }} & \multirow{3}{*}{$\mathbf{F}$} & \multirow{3}{*}{$\mathbf{P}$} \\
\hline & \multicolumn{2}{|c|}{ Group Ia } & \multicolumn{2}{|c|}{ Group Ib } & \multicolumn{2}{|c|}{ Group Ic } & & & & \\
\hline & Mean \pm SD & \begin{tabular}{|l|} 
Range \\
\end{tabular} & Mean \pm SD & Range & Mean \pm SD & Range & Mean \pm SD & Range & & \\
\hline $\mathrm{PH}$ & $7.40 \pm .03$ & $7.36-7.45$ & $7.42 \pm .04$ & 7.35-7.49 & $7.46 \pm .07^{\mathrm{ab}}$ & $7.28-7.52$ & $7.40 \pm .02^{\mathrm{c}}$ & 7.36-7.43 & 8.012 & $<0.001$ \\
\hline$\overline{\mathrm{PCO} 2}$ & $39.10 \pm 2.75$ & $36.00-44.00$ & $36.90 \pm 6.82$ & $24.00-45.00$ & $28.60 \pm 6.87^{\mathrm{ab}}$ & $20.00-51.00$ & $39.05 \pm 1.96^{\mathrm{c}}$ & $35.00-42.00$ & 18.886 & $<0.001$ \\
\hline $\mathrm{PO} 2$ & $90.85 \pm 2.08$ & $88.00-94.00$ & $88.00 \pm 2.85^{\mathrm{a}}$ & $83.00-92.00$ & $86.50 \pm 3.47^{\mathrm{a}}$ & $79.00-91.00$ & $92.80 \pm 2.17^{\mathrm{bc}}$ & $90.00-96.00$ & 21.88 & $<0.001$ \\
\hline $\mathrm{HCO} 3$ & $24.10 \pm 1.43$ & $22.00-26.20$ & $24.65 \pm 2.14$ & $21.00-28.50$ & $27.32 \pm 3.28^{\mathrm{ab}}$ & $21.00-31.00$ & $23.87 \pm 10.01^{\mathrm{c}}$ & $22.00-25.80$ & 10.989 & $<0.001$ \\
\hline $\mathrm{SO} 2$ & $96.60 \pm 1.27$ & $95.00-99.00$ & $93.85 \pm 2.18^{\mathrm{a}}$ & $91.00-97.00$ & $92.65 \pm 2.83^{\mathrm{a}}$ & $86.00-96.00$ & $96.65 \pm 10.09^{\mathrm{bc}}$ & $95.00-99.00$ & 20.701 & $<0.001$ \\
\hline $\mathrm{Na}+$ & $139.10 \pm 2.31$ & 135.00-145.00 & $140.55 \pm 3.90$ & 133.00-146.00 & $141.00 \pm 5.48$ & $130.00-148.00$ & $138.05 \pm 1.73^{\mathrm{bc}}$ & $136.00-141.00$ & 2.734 & 0.049 \\
\hline $\mathrm{K}+$ & $4.31 \pm .33$ & \begin{tabular}{|l|}
$3.89-4.80$ \\
\end{tabular} & $4.23 \pm .47$ & \begin{tabular}{|l|}
$3.56-5.04$ \\
\end{tabular} & $3.98 \pm .53^{\mathrm{a}}$ & $3.22-4.84$ & $4.45 \pm 0.27^{\mathrm{c}}$ & $4.12-4.94$ & 4.596 & 0.005 \\
\hline
\end{tabular}

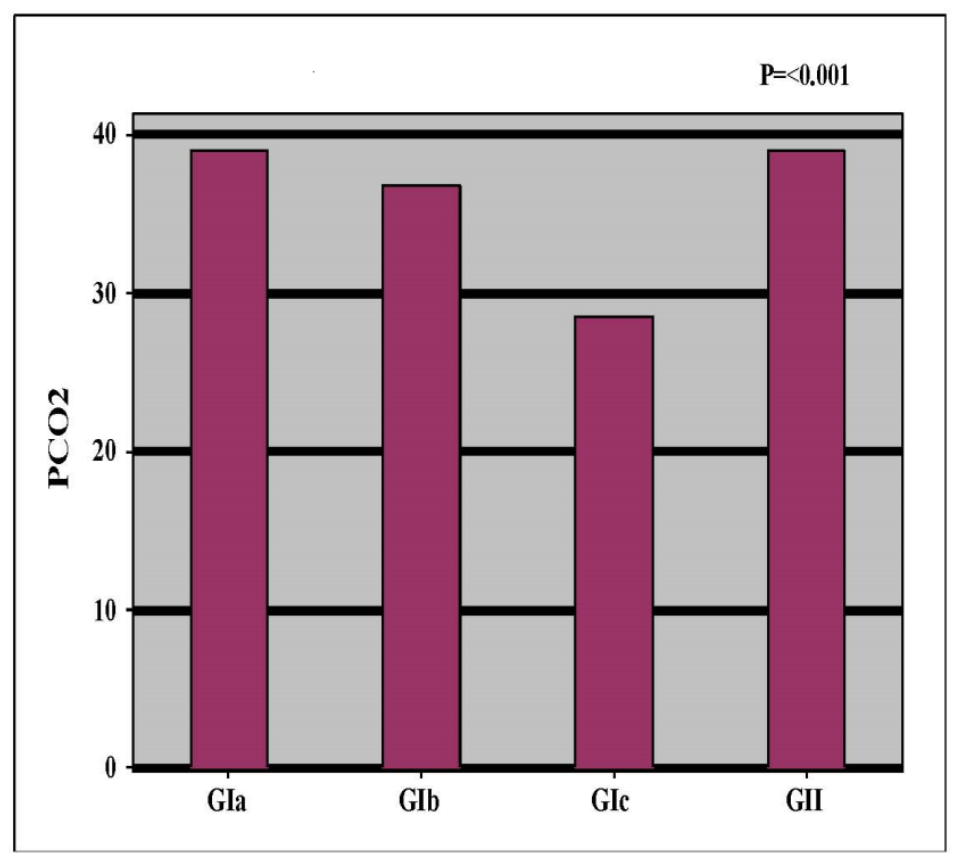

Fig. (3) : Results of $\mathrm{PCO}_{2}$ of studied groups (G: group)

Nouh et al., Afro-Egypt J Infect Endem Dis 2015; 5(1): 24-32 www.mis.zu.edu.eg/ajied/home.aspx 


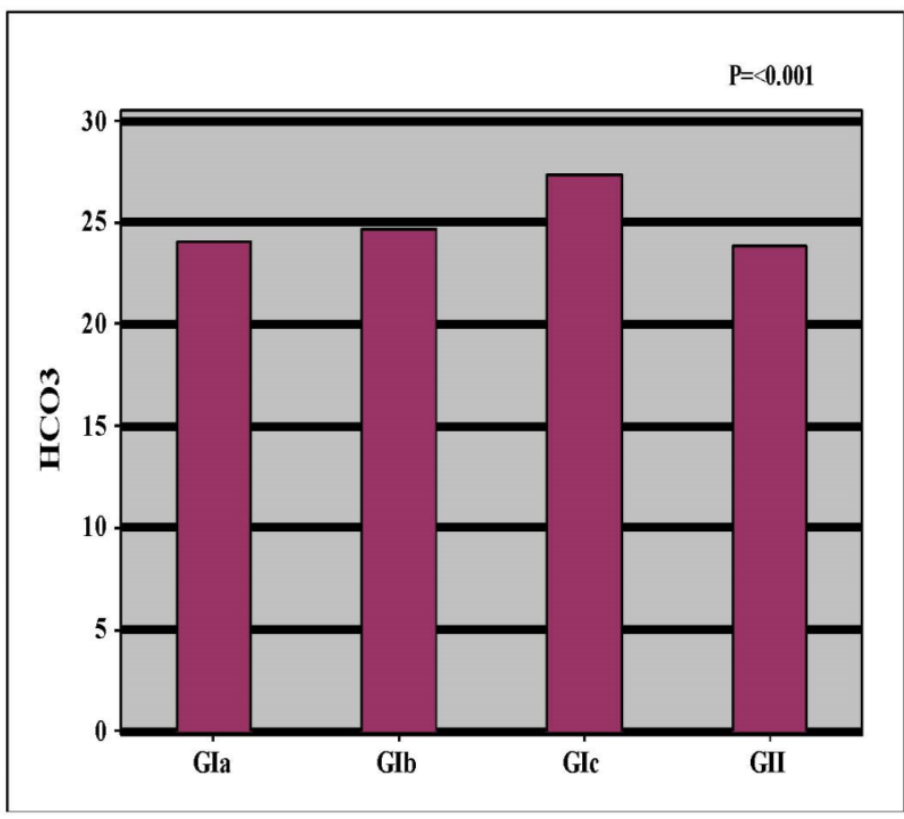

Fig. (4) : Results of Bicarbonate of studied groups (G: group)

Table (5): Acid-base status in the studied groups

\begin{tabular}{|c|c|c|c|c|c|c|c|c|c|c|}
\hline \multirow{3}{*}{ Acid-base status } & \multicolumn{6}{|c|}{ Group I } & \multirow{2}{*}{\multicolumn{2}{|c|}{ Group II }} & \multirow{3}{*}{$\mathbf{X}^{2}$} & \multirow{3}{*}{$\mathbf{P}$} \\
\hline & \multicolumn{2}{|c|}{ Group Ia } & \multicolumn{2}{|c|}{ Group Ib } & \multicolumn{2}{|c|}{ Group Ic } & & & & \\
\hline & No. & $\%$ & No. & $\%$ & No. & $\%$ & No. & $\%$ & & \\
\hline Normal & 20 & 100 & 15 & 75 & 0 & 0 & 20 & 100 & 63.7 & $<0.001$ \\
\hline Respiratory alkalosis & 0 & 0 & 4 & 20 & 14 & 70 & 0 & 0 & & \\
\hline Metabolic alkalosis & 0 & 0 & 1 & 5 & 3 & 15 & 0 & 0 & & \\
\hline Respiratory acidosis & 0 & 0 & 0 & 0 & 3 & 15 & 0 & 0 & & \\
\hline Metabolic acidosis & 0 & 0 & 0 & 0 & 0 & 0 & 0 & 0 & & \\
\hline
\end{tabular}

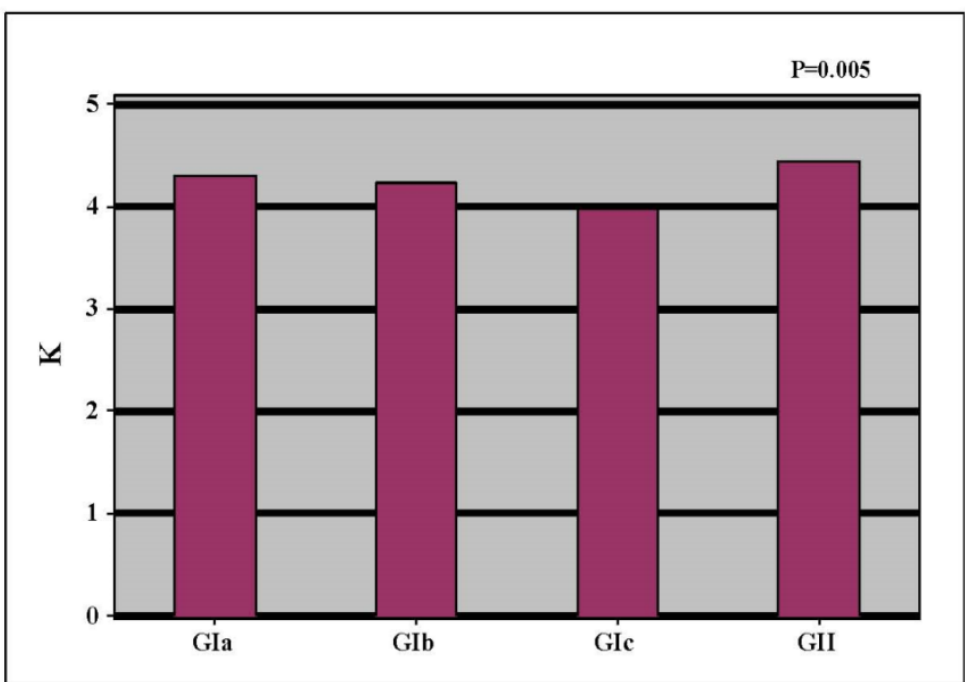

Fig. (5) : Results of Potassium of studied groups (G: group). 


\section{DISCUSSION}

Acid base disturbances are well recognized in chronic liver disease [13]. In the initial stages of portal hypertension development, there is splanchnic arterial hypertension associated with production of nitric oxide [14]. In compensated liver disease, there is an increase in cardiac index, heart rate and plasma volume. In setting of decompansated liver disease, arterial pressure decrease which lead to an increase in $\mathrm{ADH}$ receptor activity, plasma catecholamines, aldosterone and rennin aldosterone system and ADH levels causing sodium and water retention [15]. As liver's metabolic function decreases acid base disturbances often ensue [16]. Hyperventilation is almost universal finding with advanced liver disease leading to respiratory alkalosis [17].

In this study, the mean values of hemoglobin concentration and platelets counts in cirrhotic groups were significantly lower than that of healthy subjects. Also, in Group Ib and Group Ic were significantly lower than that of Group Ia and that of Group Ic was significantly lower than that in Group Ib. This could be attributed to splenic sequestration and destruction of platelets and red blood cells [18]. Also there is a redistribution of platelet mass located in enlarged spleen [19].

In this study, the mean values of serum albumin in Group Ib and Group Ic were significantly lower than that in group Ia and Group II. This reflects sever liver damage and decreased albumin synthesis [20]. These findings are consistent with the findings of Tack, et al. [21] who found that serum albumin was lower in cirrhotic patients than that of healthy control patients.

As regard INR it was significantly higher in Group Ib than in Group Ia and significantly higher in Group Ic than in Group Ia and Group Ib. Meanwhile the INR in GII lower than that in Group Ib and Group Ic, while prothrombin time was higher in cirrhotic patients than that of control patients. This could be explained by poor utilization of vitamin $\mathrm{K}$ owing to parynchymal liver disease [22].

The mean values of ALT and AST in Group Ic were significantly lower than that in Group Ia and Group Ib. This may reflect the massive destruction and loss of viable hepatocytes [23].

In present study initial assessment ABGs were done and both groups showed that significant difference in PH between Group Ic and Group Ia and Group Ib. As well as significant difference between Group II and Group Ic. This could be attributed to hypoxaemia, anaemia, hepatopulmonary syndrome, hepatic hydrothorax, hyperventilation which may be due to brain hypoxia and direct stimulation of respiratory centre by elevated progesterone level. Estradiol increase the number of progesterone receptors in animal and hence increase its overall actions [16].

Also metabolic alkalosis may be due to the use of loop diuretics which lead to increase urinary hydrogen loss. High level of aldosterone may increase urinary hydrogen loss [24].

There is low significant increase in serum $\mathrm{Na}^{+}$ between Group Ib and Group Ic than Group II. This could be explained by high level of aldosterone in case of hepatic fibrosis.

As regard $\mathrm{K}^{+}$there is low significant decrease in Group Ic in relation to Group Ia and Group II in relation to Group Ic which may be explained by by use of loop diuretics and high level of aldosterone.

Respiratory alkalosis is thought to be the most common acid base derangement found in patients with liver disease as a result of hyperventilation and an increase in blood ammonia levels. Mulhausen, et al. [25] observed the relationship of acid-base status in 91 patients with liver disease; $64 \%$ had respiratory alkalosis but all varieties of acid-base abnormalities were observed.

Funk, et al. [26] studied 50 patients with stable liver disease and 10 healthy subjects and observed that patients with the mildest form of liver disease (Child-Pugh class A) had a normal acid-base state, whereas those with class B or C had respiratory alkalosis. Proposed causative factors for respiratory alkalosis include hypoxemia in the setting of massive ascites, anemia, hepatopulmonary syndrome, hepatic hydrothorax, or bacterial infection; the exact cause of hyperventilation remains unclear but high progesterone levels owing to liver disease seems the best explanation. Patients with fulminant hepatitis and hepatic coma can have a $\mathrm{pH}$ greater than 7.50 [27].

The cause of hyperventilation is not clear; proposed causes include brain hypoxia and direct stimulation of the respiratory center by increased progesterone levels. In addition, estradiol has been proposed to be associated indirectly with respiratory alkalosis because it increases the number of progesterone receptors in animals and hence may increase its overall actions [16]. 
Progesterone is a respiratory stimulant in human beings and is degraded by the liver. Eiseman and Clark observed that there is a direct correlation with hyperventilation and ammonia; however, subsequent studies with intravenous infusion of ammonia did not produce any increase in ventilation. Chronic respiratory alkalosis, similar to hyperchloremic metabolic acidosis, presents with hypobicarbonatemia and hyperchloremia. In the absence of blood gas determination, this combination often is diagnosed erroneously as a chronic metabolic acidosis. In this respect, the urine anion gap is useful in distinguishing these 2 disorders: if a metabolic acidosis other than distal RTA is present then the urine anion gap should be negative. A positive urine anion gap in this setting suggests the presence of a respiratory alkalosis on distal RTA. A negative urine anion gap helps to rule out chronic respiratory alkalosis. In this disorder a positive urine anion gap is expected as a result of suppressed urinary acidification, which is an adaptive response to chronic alkalemia. Although the definitive diagnosis requires a blood gas, the urine gap provides an index of suspicion alerting to the possible presence of a chronic respiratory alkalosis. There are no studies validating the use of the urine anion gap in patients with respiratory alkalosis in the setting of chronic liver disease, in which ammonia levels may be increased. Respiratory acidosis may occur also, but this is rare exceptions when the patient is exposed to sedatives or in the context of associated lung disease [28].

Metabolic alkalosis is another common base disorder found in patients with liver disease, often as a result of therapy with loop diuretics. This occurs owing to increased urinary hydrogen loss from enhanced distal hydrogen secretion. High aldosterone levels and hypokalemia further increase distal hydrogen secretion. Haussinger, et al. [24] suggested that metabolic alkalosis occurs as a result of abnormal hepatic bicarbonate disposal and urea synthesis in cirrhosis.

However, Shangraw and Jahoor [29] showed that impaired urea synthesis may not precipitate metabolic alkalosis. Metabolic alkalosis often results from diuretic therapy with loop diuretics or thiazides and often is accompanied by hypokalemia. The administration of potassium or the use of potassium-sparing diuretics such as spironolactone may prevent or reduce metabolic alkalosis. Metabolic alkalosis also may occur in the setting of vomiting. As mentioned earlier, alkalosis, similar to hypokalemia, is thought to exacerbate hepatic coma; an increase in extracellular $\mathrm{pH}$ increases the conversion of ammonium to ammonia [29].

\section{CONCLUSION}

Respiratory alkalosis either alone or associated with metabolic acidosis is most common acid base disorders. So we should put in our considerations the conditions which increase this state as gastric aspiration and vomiting. Other factors implicated in mediating changes in $\mathrm{PH}$ should be studied carefully such as septic shock or haemorrhage which may lead to a metabolic acidosis. We should put in our consideration that most minor therapies such as infusion of normal saline, administration of albumin, glucose infusion and initiation of diuretic therapy, vasopressin analogs and lactulose therapy may alter delicate acid-base balance.

Funding: Non.

Conflicts of interest: The authors declare no conflicts of interest.

Ethical approval: The study was approved by the Ethical Committee of Menoufia Faculty of Medicine and a written informed consent was taken from each participant that follows principles in the Declaration of Helsinki.

\section{REFERENCES}

1. Oster J.R., Pertez G.O. Acid-base disturbances in liver disease. J Heptol 1986; 2: 229-306.

2. Ordialis Fernandez J.J., Fernandez Moya A., Linares Rodriuez A, Colubi Colubi L, Nistal de Paz F, Allende González A., et al. Study of arterial blood gases in liver cirrhosis with and without ascites. REV Esp. Enferm dig 1996; 88:3:197-201

3. Li X.M., Li Y.X., Meng Q.H, Duan ZH, Hou W, Li J. Characteristic of acid base balance in patients with chronic severe hepatitis. Zhonghua yi xue za zhi 2006; 15, 86:30:2131-3

4. Emmett M., Seldin D.W. Clinical syndromes of metabolic acidosis and metabolic alkalosis. In: Seldin, Giebisch. The Kidney: Physiology and Pathophysiology. New York, Raven Press 1999; Pp 1567-639.

5. Haussinger D., Steeb R., Gerok.W. Ammonium bicarbonate haemostasis in chronic liver disease . Klin Wonchester1990;68:75. 
6. Ahya S.N.; Jose Soler M.; Levitsky J., Battle D. Acid-base and potassium disorders in liver disease. Semin Nephrol 2006; 26:466-470.

7. Hu yangteng, Yu Shi-yuan, Ren Cheng-Shan. A study of acid-base disturbance in hepatic encephalopathy. Department of Internal Medicine, Second Affiliated Hospital, Third Military Medical College, Chongqing. Chinese journal of internal medicine 1998; 27.

8. Hoffman R., Benz E.J., Shattil S.J. Basic principles and practice. Churchill living stone Inc, USA. 1991; pp 1-120.

9. Balistreri W.F., Shaw L.M. Biochemical assessment of liver functions in: Tietz $\mathrm{N}$ ed. Textbook of clinical chemistry. WB Saunders company, Philadelphia 1986; pp 1373.

10. Sack D.B. Methods of determination of glycated hemoglobin, carbohydrates. In: Teitz fundamental of clinical chemistry 5th edition, 2001; 12201250.

11. Jaffe M. Estimation of creatinine in serum. Physiol. Chem1986;10:391.

12. Aaron S.D., Vandemheen K.L., Naftel S.A., Lewis M.J., Rodger M.A.: "Topical tetracaine prior to arterial puncture: a randomized, placebocontrolled clinical trial". Respir Med 2003;97 :11: 1195-1199.

13. Zavagli G., Ricci G., Bader G. The importance of the highest normokalemia in the treatment of early hepatic encephalopathy. Miner Electrolyte Metab 1993;19:362-367.

14. Cardenas A., Arroyo V. Mechanisms of water and sodium retention in cirrhosis and the pathogenesis of ascites. Best Pract Res Clin Endocrinal Metab 2003;17:607-622.

15. Cardenas A., Arroyo V. Refractory ascites. Dig Dis 2005; 23:30-38.

16. Lustik S.J., Chhibber A.K., Kolano J.W. The hyperventilation of cirrhosis: Progesterone and estradiol effects. Hepatology 1997; 25:55-58.

17. Krapf R., Beeler I., Hertner D., Hulter HN. Chronic respiratory alkalosis. The effect of sustained hyperventilation on renal regulation of acid-base equilibrium. $N$ Engl J Med 1991; 324:1394-140

18. Toghill P.J., Green S, Ferguson F. Platelet dynamics in chronic liver disease with special reference to the role of the spleen. J clin Pathol 1977 ; 30: 367-71.

19. Pilette C., Oberti F., Aube C. Non invasive diagnosis of esophageal varices in chronic liver diseases.J Hepatol 1999; 31:867-73.
20. Veldhuyzen van Zanten SJ, Depla AC, Dekker PC, Langius FA, Wesche MF, Sanders GT, et al. The clinical importance of routine measurement of liver enzymes, totalproteins and albumin in general medicine outpateintts clinc :a prospective study. N Engl J Med1992; 40 :53.

21. Tacke F., Schoffski P., Luedde T., Meier PN, Ganser A, Manns MP et al. Analysis of factors contributing to higher erythropoietin levels in patients with chronic liver disease. Scand. J. Gastroenterol2004 ; 39: 259-266.

22. Suehiro T., Sugimachi K., Matsumata T., Itasaka H, Taketomi A, Maeda T. Protein induced by vitamin $\mathrm{K}$ absence or antagonist II as aprognistic marker in HCC: comparison with alfa fetoprotein. Cancer 1994; 73: 2464.

23. Cohen J.A., Kaplan M.M. The SGPT/SGOT ratio: an indicator of alcoholic liver disease. Dig Dis Sci 1979; 24 :8335.

24. Haussinger D., Steeb R., Gerok W. Metabolic alkalosis as driving force for urea synthesis in liver disease: Pathogenetic model and therapeutic implications. Clin Invest 1992; 70:411-415.

25. Mulhausen R., Eichenholz A., Blumentals A. Acid-base disturbances in patients with cirrhosis of the liver. Medicine (Baltimore) 1967; 46:185189.

26. Funk GC, Doberer D, Osterreicher C, PeckRadosavljevic M, Schmid M, Schneeweiss B. Equilibrium of acidifying and alkalinizing metabolic acid-base disorders in cirrhosis. Liver Int2005; 25:505-512.

27. Record C.O., Iles R.A., Cohen R.D., Williams R. Acid-base and metabolic disturbances in fulminant hepatic failure. Gut 1975; 16:144-149.

28. Eiseman B., Clark G.M. Studies in ammonia metabolism. III. The experimental production of coma by carotid arterial infusion of ammonium salts. Surgery 1958; 43.476-485.

29. Shangraw R.E, Jahoor F. Effect of liver disease and transplantation on urea synthesis in humans: Relationship to acid-base status. Am J Physiol 1999; 276: G1145-G1152.

Peer reviewer: Mohamed Saleh, Lecturer of Anesthesia and Intensive care, Faculty of Medicine, Ain Shams University, Egypt . Mohamed Ibrahim El-Najjar, Head of Internal Medicine Department, Taymaa General Hospital, Tabuk, KSA.

Editor: Mohamed H Emara, Lecturer of Tropical Medicine and Hepatogastroenterology, Faculty of Medicine, Zagazig University, Egypt 